\title{
Analysis of a combined cycle propulsion system for STRATOFLY hypersonic vehicle over an extended trajectory
}

\author{
Ali Can Ispir ${ }^{1,}$, Pedro Miguel Gonçalves ${ }^{1}$, and Bayindir H. Saracoglu ${ }^{1}$ \\ ${ }^{1}$ von Karman Institute for fluid dynamics, Aeronautics and Aerospace Department, 1640 Sint- \\ Genesius-Rode, Belgium
}

\begin{abstract}
Hypersonic civil aviation is an important enabler for extremely shorter flight durations for long-haul routes and using unexploited flight altitudes. Combined cycle engine concepts providing extended flight capabilities, i.e. propelling the aircraft from take-off to hypersonic speeds, are proposed to achieve high-speed civil air transportation. STRATOFLY project is a continuation of former European efforts in hypersonic research and aims at developing a commercial reusable vehicle for cruise speed of Mach 8 at stratospheric altitudes as high as $35 \mathrm{~km}$ above ground level. The propulsion plant of STRATOFLY aircraft consists of combination of two different type of engines: an array of air turbo rockets and a dual mode ramjet/scramjet. In the present study, 1D transient thermodynamic simulations for this combined cycle propulsion plant have been conducted between Mach 0 to 8 by utilizing 1D inviscid flow transport relations, numerical tools available in EcosimPro software platform and the European Space Propulsion System Simulation libraries. The optimized engine parameters are achieved by coupling EcosimPro software with Computer Aided Design Optimization which is a differential evolution algorithm developed at the von Karman Institute.
\end{abstract}

\section{Introduction}

Hypersonic civil aircraft concepts enable extremely short flight duration especially in long route journeys. The framework of STRATOFLY MR3 civil aircraft development is being built on the vast European heritage on hypersonic research such as LAPCAT I and II, ATTLAS I and II, FAST20XX, HIKARI, HEXAFLY etc [1]. The aircraft is planned to carry 300 passengers and fly at stratospheric altitudes with cruise speed of Mach $8[2,3]$. The combined cycle propulsion plant of the aircraft relies on six air turbo rocket (ATR) engines operated from take-off to hypersonic speeds (Mach 4.5) and a unique dual mode ramjet (DMR) engine which can operate in both ramjet and scramjet mode. After Mach 1.5, it starts operating in ramjet mode until cruise speed of Mach 4.5. When the aircraft reaches hypersonic cruise conditions, ATR engines are completely shut down and it is only propelled by DMR engine up to Mach 8 [4]. To ensure safety, operational reliability and provide required thrust along the whole flight trajectory, determining the operational and boundary conditions of the engine component is essential. Hence, investigation of the thermodynamic cycle of the engine and estimation of engine performance for all cruise conditions, i.e., subsonic, supersonic and hypersonic, are necessary.

ATR engines are responsible to propel the aircraft during the subsonic and supersonic cruise segments. Each ATR engine consists of a combustion chamber, an air-compressor, a hydrogen turbine and a turbopump. There is also a regenerator system comprised of heat

\footnotetext{
*Corresponding author: ali.can.ispir@vki.ac.be
} 
exchangers in order to pick-up heat from heat sinks in the cycle such as combustion chamber and nozzle. After the fuel flow is pumped out of the tanks, it passes through the regenerator channels and the enthalpy is increased. When it reaches the inlet of the turbine, the enthalpy must be sufficient so that the turbine can produce enough shaft power for the compressor and fuel pump. In the case the heat exchangers cannot heat up fuel flow or/and the flow cannot be expanded through the turbine stages, the thrust will decrease immediately $[4,5]$. This means that there is a trade-off between the regenerator and turbine complexity. If the fuel flow is over-expanded, heat exchanger capacity can be kept as small. On the contrary, if the pressure ratio of the turbine is small, a high capacity regenerator is required. 1D transient thermodynamic analysis is very important to determine engine operational and boundary conditions. In present study, EcosimPro and European Space Propulsion System Simulations (ESPSS) libraries [6] developed by European Space Agency (ESA), were used to accomplish this. Moreover, an in-house code optimizer Computer Aided Design Optimization (CADO) [7] was coupled with the EcosimPro to find suitable conditions for best engine performance to minimize fuel consumption without sacrificing required thrust level by the flight trajectory. The optimization is conducted to resolve trade-off between turbine and regenerator complexity and minimizing overall weight of these components by finding best regenerator dimensions and turbine pressure ratio.

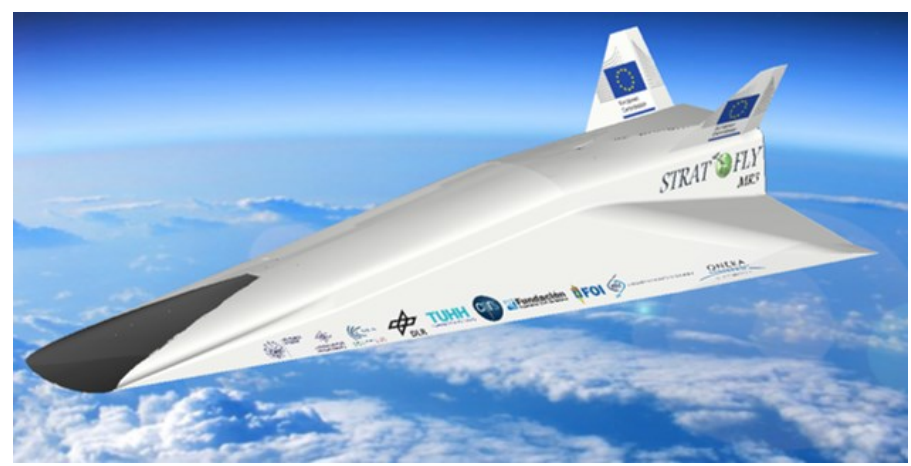

Fig. 1. A conceptual view of STRATOFLY MR3 aircraft.

After Mach 4.5, the aircraft is only propelled by DMR engine during the hypersonic cruise (Mach $4.5-8$ ). The DMR engine of STRATOFLY MR3 aircraft is comprised of supersonic intake, isolator, combustor and diverged nozzle. Even though DMR engine structure seems simpler as compared to ATR engine, flow physics are very complex in terms of shocks and expansion waves along the engine duct, fuel - air mixing and combustion [8]. Temperature and pressure rise along the duct, speed of sound change should be modelled, controlled and investigated in detail to make sure the propulsion works properly and meet the flight trajectory requirements. In the STRATOFLY MR3, this paper is also devoted to conduct 1D simulations for estimating DMR engine performance along hypersonic part of the trajectory. For this purpose, 1D inviscid steady flow transport equations equipped with finite rate chemistry were modelled [9].

\section{Computational Model}

\subsection{EcosimPro}

EcosimPro is an object-oriented multidisciplinary simulation platform, enabling users to build thermodynamic models of real continuous systems and simulate in either transient 
or steady-state by using its own EL language [10]. The numerical model for a physical system is built by assembling components representing physical behaviour of the real systems and subsystems (i.e., valves, injectors, pumps), including suitable mathematical models. The components are connected via ports defining set of variables to be interchanged in the connections. The mathematical formulations and functions of each component are embedded to partitions. All ports, components and partitions are included in the libraries. EcosimPro can be coupled with various libraries to extend its capability, one of the library set is ESPSS developed by European space Agency (ESA) to model rocket and satellite propulsion systems [6].

A set of differential-algebraic equations and topology are created by components' mathematical formulations. By the equation set, a state vector $\mathrm{x}(\mathrm{t})$ is given and boundary and initial conditions $\mathrm{x}\left(\mathrm{t}_{0}\right)$ have to be provided for the solution. The equation system is defined by F;

$$
F(\dot{x}, x, t ; u)=0 \quad x\left(t_{0}\right)=x_{0}
$$

By providing appropriate initial conditions $\mathrm{x}(0)$ and control law $\mathrm{u}(\mathrm{t})$, the system of equations $\mathrm{F}$ can be integrated by using Differential-Algebraic System Solver algorithm (DASSL) [11]. The solution uses a backward differentiation in place of time derivative $u(t)$ and applies an implicit Newton-Raphson method with time steps automatically set up by the algorithm itself depending on the evolution of the simulation.

\subsection{CADO}

The Computer Aided Design and Optimization (CADO) tool developed at the von Karman Institute uses an evaluation algorithm which is based on Darwinian theory, populations of individuals can evolve over a search space in order to adapt to conditions and survive. The evolution of the individuals happens within three different mechanisms such as mutation, crossover and selection. The individuals best fit to the environment get a chance to survive and reproduce [7]. An individual $\mathrm{x}$ is comprised of design variables $\left(\mathrm{x}_{1}, \mathrm{x}_{2}\right.$, etc). A set of individuals is a population.

$$
\vec{x}_{t}=\left(x_{1}, x_{2}, \ldots, x_{n}\right)
$$

In the evolution process of individual $x_{t}$, three random vectors $\left(a_{t}, b_{t}, c_{t}\right)$ are selected such that $\mathrm{a}_{\mathrm{t}} \neq \mathrm{b}_{\mathrm{t}} \neq \mathrm{c}_{\mathrm{t}} \neq \mathrm{x}_{\mathrm{t}}$. A trial vector is defined through mutation process as,

$$
y_{i}=a_{i}+F \cdot\left(b_{i}-c_{i}\right) \quad i=1 . . n
$$

$\mathrm{F}$ is user defined constant to control amplification factor $\left(b_{i}-c_{i}\right)$. The candidate vector $z$ is obtained through a process called crossover Genetic Algorithms (GA) analogy by combining $\mathrm{x}_{\mathrm{t}}$ and $\mathrm{y}_{\mathrm{t}}$, as defined below:

$$
z_{i}=\left\{\begin{array}{ll}
y_{i} & \text { if } \quad r_{i} \leq C \\
x_{i} & \text { if } \quad r_{i}>C
\end{array} \quad i=1 . . n\right.
$$


where $r_{i}$ is a uniformly distributed random variable $(0 \leq \mathrm{ri} \leq 1)$ and $\mathrm{C}$ is a user defined constant. The final step of the evolution is selection process for the minimization of the objective function $\mathrm{f}\left(\mathrm{x}_{\mathrm{t}}\right)$ to determine best candidate,

$$
\overrightarrow{\mathbf{x}}_{t+1}= \begin{cases}\overrightarrow{\mathbf{z}} & \text { if } \quad f(\mathbf{z}) \leq f\left(\overrightarrow{\mathbf{x}}_{t}\right) \\ \overrightarrow{\mathbf{x}}_{t} & \text { if } \quad f(\mathbf{z})>f\left(\overrightarrow{\mathbf{x}}_{t}\right)\end{cases}
$$

\subsection{Numerical Model}

The combined cycle propulsion plant consists of six ATR engines located at both sides of the plant and one DMR engine having dorsal orientation. The intake and nozzle are common to both engines; incoming air stream to the inlet is split up two, upper part goes to DMR engine and other part passes to ATR channels. Exhaust gases are merged in the nozzle section. DMR engine inlet section is always kept as open thereby when the engine does not operate, by-passed air flow can contribute the thrust level [12]. The general view of the engine scheme is shown in Fig. 2. Three mechanisms were created in EcosimPro platform accordingly cruise conditions to assess the engine performance along the whole flight trajectory.

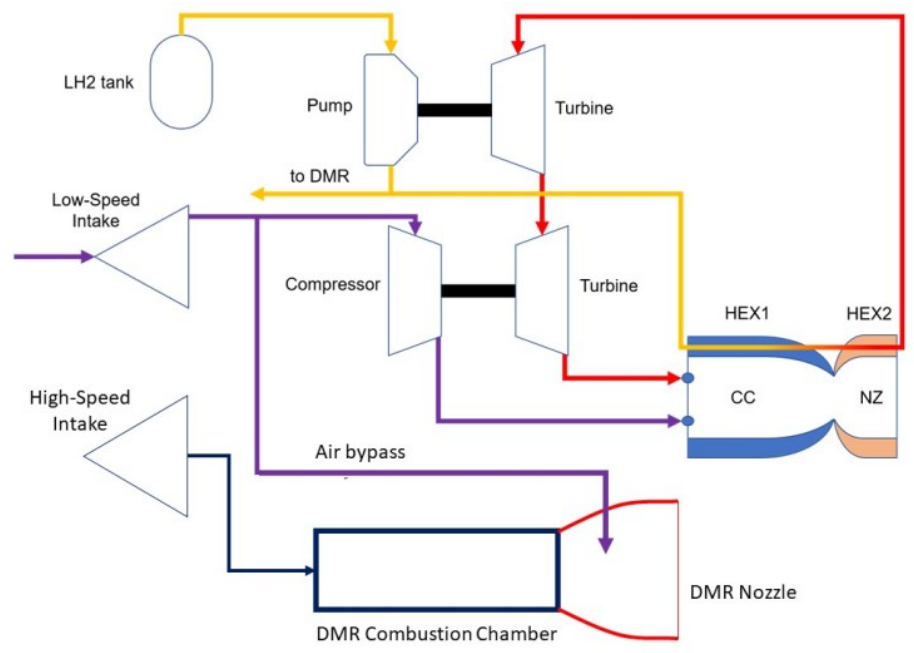

Fig. 2. Propulsion plant schematic.

\subsubsection{Subsonic and supersonic cruises}

STARTOFLY MR3 aircraft is propelled by ATR engines during subsonic and supersonic cruises. DMR engine is slightly started its operation in ramjet mode along the supersonic cruise. Subsonic engine scheme is comprised only ATR engine while supersonic scheme involves ATR and DMR engines combined. 
Total pressure recovery and mass capture ratio across the intake of the aircraft for both ATR and DMR sections were calculated in previous CFD studies [13]. The adiabatic efficiencies of the air compressor, pump and turbine are assumed constant, as $88 \%, 70 \%$ and $60 \%$, respectively. Total pressure drop through the fuel injectors and combustors are given as $20 \%$ and $5 \%$, respectively [13]. The flow inside the engine duct during the compression and expansion is solved by using isentropic relations and these loss coefficients. Heat pick-up rate in the regenerator is calculated with convective heat transfer equation, where the heat transfer coefficient is a function of Nusselt, Reynolds and Prandtl numbers ( $\mathrm{Nu}, \mathrm{Re}$ and $\mathrm{Pr}$ respectively) [4]. The friction factor is computed using the Churchill correlation [14]. In the ATR combustion chamber, the product is assumed to be at chemical equilibrium and fuel-air mixture is assumed as calorically perfect. The molar composition of the mixture $\left(\mathrm{N}_{1}, \mathrm{~N}_{2}, \mathrm{~N}_{3}, \ldots, \mathrm{N}_{\mathrm{S}}\right)$ calculated by minimizing the Gibbs potential $(\mathrm{G})$ energy in chemical equlibirum at pressure $\mathrm{P}$ and temperature T. For DMR combustor, the flow is choked at the throat of the combustor. The combustion is thought to be adiabatic and occur in constant stagnation pressure in subsonic conditions since incoming supersonic flow decelerates across a normal shock wave in the isolator. The products are in chemical equilibirium likely to numerical model of ATR combustor chamber and the molar composition is calculated by minimizing Gibbs energy. The amount of fuel is calculated by mass flow parameter expression [15].

\subsubsection{Hypersonic cruise}

In order to assess combined cycle propulsion plant performance along the hypersonic regime of the trajectory, a 1D propulsion tool was developed [16] and inviscid steady flow transport equations and combustion chemistry were embedded to the tool [9]. Three main governing equations (mass, momentum and energy) are implemented by imposing perfect gas assumption. In order to solve the mass fractions after reaction and fuel injection, species equation are added to the equation set, reaction rates are calculated via finite chemistry method and Arrhenius approach.

\subsubsection{Engine performance}

The engine performance is evaluated in terms of three parameters: specific thrust, impulse and installed/uninstalled thrust. The uninstalled thrust is calculated by taking difference at intake (station $\mathrm{j}$ ) and outlet (station $\infty$ ) of the engine duct:

$$
F_{u}=\eta_{n}(\dot{m} U)_{j}-(\dot{m} U)_{\infty}+\left(p_{j}-p_{\infty}\right) A_{j}
$$

By subtracting drag force, net thrust can be obtained;

$$
F=F_{u}-\frac{1}{2}(\dot{m} U)_{\infty} C_{x} A_{\infty}
$$

where $C_{x}$ and $A_{\infty}$ are drag coefficient and nozzle exit area, respectively. By dividing net thrust to mass flow rate of air stream and fuel, specific thrust $T_{\mathrm{sp}}$ and impulse $\mathrm{I}_{\mathrm{sp}}$ are obtained;

$$
I_{s p}=\frac{F}{\dot{m}_{H_{2}}} \& T_{s p}=\frac{F}{\dot{m}_{\text {air }}}
$$




\section{Numerical Results}

\subsection{STRATOFLY MR3 Aircraft flight trajectory}

In 1D simulations, the inlet flow conditions were defined by considering STRATOFLY MR3 aircraft flight trajectory. The trajectory is comprised two parts: descending and ascending. 12 specific cruise speeds (at Mach 0.5, 0.75, 0.9, 1.5, 2.0, 3.0, 4.0, 4.5, 5.0, 6.0, 7.0 and 8.0) were investigated at subsonic, supersonic and hypersonic regime. Along the trajectory, thrust requirements for these specific cruise speeds under investigation are given as $1500,1330,960,2150,2150,1860,1220,1400,1330,1020,872$ and $417 \mathrm{kN}$ for the corresponding Mach numbers. Throughout the numerical simulations, the combined cycle propulsion plant should demonstrate higher performance than these values.

\subsection{Verification of engine schemes}

Data for the engine performance in supersonic and hypersonic flight regimes are available in literature [4,19]. EcosimPro schemes was verified with performance parameters of LAPCAT-II MR 2.4 aircraft. The new 1D propulsion tool was verified by comparing pressure rise along the engine duct with numerical study by Piscitelli et al. $[19,20]$ at cruise speed of Mach 8 conditions. The pressure curve obtained in the simulation of the propulsion tool was drawn from the intake of the combustor since aerodynamic data of intake and isolator obtained by the CFD simulations was imposed to the tool.

\subsection{Performance analysis over the extended flight trajectory}

The performance analysis over the extended STRATOFLY MR3 trajectory was done for the cruise speeds under investigation and the optimized results are given in Table 1.

Table 3 Engine performance values over the extended flight trajectory

\begin{tabular}{|c|c|c|c|c|c|c|}
\hline Mach \# & $\begin{array}{c}\text { Mixing } \\
\text { length }[\mathrm{m}]\end{array}$ & $\begin{array}{c}\text { Fuel mass } \\
\text { gradient } \\
{[\mathrm{kg} / \mathrm{s}-\mathrm{m}]}\end{array}$ & $\begin{array}{c}\text { Fuel } \\
\text { consumption } \\
{[\mathrm{kg} / \mathrm{s}]}\end{array}$ & $\begin{array}{c}\text { Combustor } \\
\text { throat area } \\
{\left[\mathrm{m}^{2}\right]}\end{array}$ & $\begin{array}{c}\text { Mixture } \\
\text { ratio }\end{array}$ & $\begin{array}{c}\text { Net thrust } \\
{[\mathrm{kN}]}\end{array}$ \\
\hline 0.5 & - & - & 58 & 17.37 & 31 & 1502 \\
\hline 0.75 & - & - & 74.5 & 17.37 & 45 & 2227.2 \\
\hline 0.9 & - & - & 53 & 17.37 & 38 & 1612 \\
\hline 1.5 & - & - & 59.2 & 17.37 & 30 & 2220.6 \\
\hline 2.0 & - & - & 53.8 & 17.37 & 35 & 2381.3 \\
\hline 3.0 & - & - & 50.7 & 14.43 & 36 & 2175.4 \\
\hline 4.0 & - & - & 24.3 & 3.98 & 68 & 1223.2 \\
\hline 4.5 & - & - & 35.8 & 2.8 & 44.9 & 1586.7 \\
\hline 5.0 & 0.4 & 540 & 216 & 4.86 & 11 & 1340 \\
\hline 6.0 & 0.5 & 290 & 145 & 4.86 & 16 & 1031 \\
\hline 7.0 & 0.6 & 205 & 123 & 4.86 & 12 & 891 \\
\hline 8.0 & 0.7 & 120 & 84 & 4.86 & 18.7 & 423 \\
\hline
\end{tabular}

Since mixing model was not yet imposed to the propulsion tool, fuel mass flow gradient and mixing length of hydrogen fuel - air mixture were parameterized in the hypersonic engine assessment. The mixing properties for hypersonic engine depicted in the table were 
selected to minimize the fuel consumption. In the Table 1, mixture ratio represents the ratio between air mass flow rate and fuel mass flow rate.

\section{Conclusion}

A numerical scheme for the subsonic and supersonic parts of combined cycle propulsion plant of STRATOFLY MR3 aircraft was implemented in EcosimPro software. The hypersonic assessment was done by solving $1 \mathrm{D}$ inviscid steady flow transport equations and finite rate chemistry for supersonic combustion. The numerical models for three engine schemes were verified by using available data in the literature. For hypersonic engine, since there is no mixing model implemented to the tool, mixing properties such as mixing length and fuel mass gradient were investigated along a range, optimized mixing properties were demonstrated in the results.

The optimization of operational and boundary conditions of ATR engine components was done by coupling EcosimPro and CADO tools. The design space is comprised of combustor throat area, combustion chamber pressure, mixture ratio and flight conditions. The main aim of the optimization is to minimize fuel consumption without sacrificing thrust level required by the flight trajectory. The second aim is to resolve the tradeoff between regenerator and turbine complexity by minimizing the overall system weight. The throat area of the combustor remained constant until cruise speed of Mach 3, then it was gradually closed. After Mach 4.5, there is no flow passing through the ATR channels. On the other hand, the throat area of combustor of DMR engine is always kept constant. The flow regime changes with the effective flow area which is a result of boundary layer propagation along the engine duct.

The trajectory requirements were fulfilled at all cruise conditions under investigation. The fuel consumption was found higher during hypersonic acceleration than subsonic and supersonic cruises. One reason is that DMR is only engine responsible for thrust production even though the thrust requirements are lower during the hypersonic cruise.

This project has received funding from the European Union's Horizon 2020 research and innovation program under grant agreement No 769246.

\section{References}

1. Roncioni, P., Natale, P., Marini, M., Langener, T., \& Steelant, J. (2013, September). Numerical simulations of the LAPCAT MR-2 vehicle scramjet engine. In 21st International Symposium Air Breathing Engines, ISABE-2013-1656, American Institute of Aeronautics and Astronautics.

2. Steelant, J., Langener, T., Flight, H., Engine, C. C., \& Ramjet, D. M. (2014). The LAPCAT-MR2 hypersonic cruiser concept. ratio, 2, 2.

3. Steelant, J. (2011, April). Sustained hypersonic flight in Europe: first technology achievements within LAPCAT II. In 17th AIAA International Space Planes and Hypersonic Systems and Technologies Conference (p. 2243).

4. Fernández Villacé, V. (2013). Simulation, Design and Analysis of Air-Breathing Combined-Cycle Engines for High Speed Propulsion (Doctoral dissertation, Aeronauticos). 
5. Fernández-Villacé, V., \& Paniagua, G. (2010). Simulation of a combined cycle for high speed propulsion. In 48th AIAA Aerospace Sciences Meeting Including the New Horizons Forum and Aerospace Exposition (p. 1125).

6. Moral, J., Pérez Vara, R., Steelant, J., \& De Rosa, M. (2010). ESPSS simulation platform. Space Propulsion.

7. Verstraete, T. (2010, September). CADO: a computer aided design and optimization tool for turbomachinery applications. In 2nd Int. Conf. on Engineering Optimization, Lisbon, Portugal, September (pp. 6-9).

8. Micka, D. J., \& Driscoll, J. F. (2009). Combustion characteristics of a dual-mode scramjet combustor with cavity flameholder. Proceedings of the combustion institute, 32(2), 2397-2404.

9. Torrez, S., Scholten, N., Micka, D., Driscoll, J., Bolender, M., Doman, D., \& Oppenheimer, M. (2008, July). A scramjet engine model including effects of precombustion shocks and dissociation. In 44th AIAA/ASME/SAE/ASEE Joint Propulsion Conference \& Exhibit (p. 4619).

10. EcosimPro. Modelling a Simulation Software. Installation \& Getting Started Guide. Version 5.2. Madrid, EA International.

11. Petzold, L. R. (1982). Description of DASSL: a differential/algebraic system solver (No. SAND-82-8637; CONF-820810-21). Sandia National Labs., Livermore, CA (USA).

12. Fernández-Villace, V., Paniagua, G., \& Steelant, J. (2014). Installed performance evaluation of an air turbo-rocket expander engine. Aerospace science and technology, 35, 63-79.

13. Meerts, C., Steelant, J., \& Hendrick, P. (2011, May). Preliminary design of the low speed propulsion air intake of the LAPCAT-MR2 aircraft. In 7th European Symposium on Aerothermodynamics, number ESA-SP-692 in ESA Special Publications, European Space Agency.

14. Churchill, S. W., \& Usagi, R. (1972). A general expression for the correlation of rates of transfer and other phenomena. AIChE Journal, 18(6), 1121-1128.

15. Heiser, W. H., \& Pratt, D. T. (1994). Hypersonic airbreathing propulsion. Aiaa.

16. Ispir, A. C., \& Saracoglu, B. H. (2019). Development of a 1D dual mode scramjet model for a hypersonic civil aircraft. In AIAA Propulsion and Energy 2019 Forum (p. 3842).

17. O'Brien, T. F., Starkey, R. P., \& Lewis, M. J. (2001). Quasi-one-dimensional highspeed engine model with finite-rate chemistry. Journal of propulsion and power, 17(6), 1366-1374.

18. Riehmer, J., \& Gülhan, A. (2011, May). Design of a Scramjet Nozzle with Streamline Tracing Technique and Reference Temperature Method. In 7th Aerodynamics Symposium on Space Vehicles.

19. Piscitelli, F., Cutrone, L., Pezzella, G., Roncioni, P., \& Marini, M. (2017). Nose-to-tail analysis of an airbreathing hypersonic vehicle using an in-house simplified tool. Acta Astronautica, 136, 148-158.

20. Goncalves, P. M., Ispir, A. C., \& Saracoglu, B. H. (2019). Development and optimization of a hypersonic civil aircraft propulsion plant with regenerator system. In AIAA Propulsion and Energy 2019 Forum (p. 4421). 